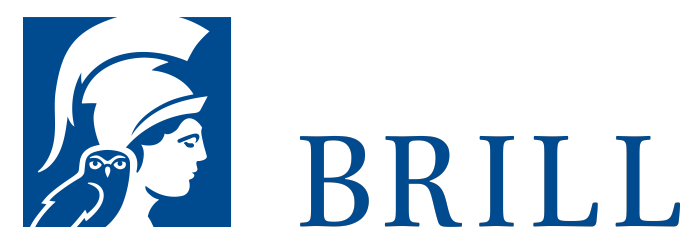

\section{In vivo - in vitro}

Zukünftige Anforderungen an die tierische Zellkultur

Author: Günter R. Fuhr

Die Nordrhein-Westfälische Akademie der Wissenschaften und der Künste ist eine Vereinigung der führenden Forscherinnen und Forscher des Landes. Sie wurde 1970 als Nachfolgeeinrichtung der Arbeitsgemeinschaft für Forschung des Landes Nordrhein-Westfalen gegründet. Die Akademie ist in drei wissenschaftliche Klassen für Geisteswissenschaften, für Naturwissenschaften und Medizin sowie für Ingenieur- und Wirtschaftswissenschaften und in eine Klasse der Künste gegliedert.

Mit Publikationen zu den wissenschaftlichen Vorträgen in den Klassensitzungen, zu öffentlichen Veranstaltungen und Symposien will die Akademie die Fach- und allgemeine Öffentlichkeit über die Arbeiten der Akademie und ihrer Forschungsstellen informieren.

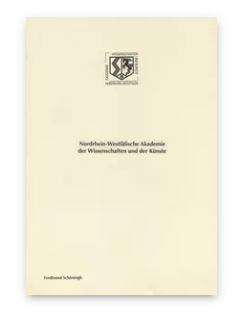

Pages: 28 Seiten

Language:

German

Subjects:

General,

Philosophy

Publisher: Brill |

Schöningh

Series:

Nordrhein Westfälische

Akademie der

Wissenschafte - Ingenieurund

Wirtschaftswissenschaften, Volume: 22

E-Book (PDF)

Released online:

og Dec 2019

ISBN: 978-3-

657-76566-9

List price

Paperback

Publication date:

21 May 2008

ISBN: 978-35०6-76566-6

List price 
For more information see brill.com

Order information: Order online at brill.com +44330 333 0049 | customerservices@brill.com Submission information: brill.com/authors

Titles published by Brill | Fink, Brill | mentis or Brill | Schöningh: +49(o)715413279216| brill@brocom.de 